\title{
Robust Control of Aeronautical Electrical Generators for Energy Management Applications
}

\author{
Giacomo Canciello, Alberto Cavallo, and Beniamino Guida \\ Department of Industrial and Information Engineering, University of Campania, 81031 Aversa, Italy \\ Correspondence should be addressed to Alberto Cavallo; alberto.cavallo@unicampania.it
}

Received 27 February 2017; Accepted 15 June 2017; Published 6 August 2017

Academic Editor: Davide Micheli

Copyright (C) 2017 Giacomo Canciello et al. This is an open access article distributed under the Creative Commons Attribution License, which permits unrestricted use, distribution, and reproduction in any medium, provided the original work is properly cited.

\begin{abstract}
A new strategy for the control of aeronautical electrical generators via sliding manifold selection is proposed, with an associated innovative intelligent energy management strategy used for efficient power transfer between two sources providing energy to aeronautical loads, having different functionalities and priorities. Electric generators used for aeronautical application involve several machines, including a main generator and an exciter. Standard regulators (PI or PID-like) are normally used for the rectification of the generator voltage to be used to supply a high-voltage DC bus. The regulation is obtained by acting on a DC/DC converter that imposes the field voltage of the exciter. In this paper, the field voltage is fed to the generator windings by using a second-order sliding mode controller, resulting into a stable, robust (against disturbances) action and a fast convergence to the desired reference. By using this strategy, an energy management strategy is proposed that dynamically changes the voltage set point, in order to intelligently transfer power between two voltage busses. Detailed simulation results are provided in order to show the effectiveness of the proposed energy management strategy in different scenarios.
\end{abstract}

\section{Introduction}

In the frame of More Electric Aircraft [1], a great emphasis is given about the generation stage, referring to the possibility of providing new "greener" generators, that is, generators with reduced weight and consequently fuel consumption reduction. In addition to increased power density and reduced weight of structures, new improvements about the generation stage for more electrical aircraft can involve also the control stage, which can be optimized for a variety of objectives (e.g., to manage innovative devices for noise and vibrations onboard [2]).

Usually, synchronous machines are used as electric generators. The voltage produced by the generator is distributed to the loads on an AC bus. Moreover, a rectifier or an Autotransformer Rectifier Unit (ATRU) is used, and from the AC bus a derived DC bus is obtained. The control strategy, one of the main points of the paper, is devoted to keep the generator voltage (and, in turn, the DC voltage bus) at a prescribed level. Note that the prescribed level, though constant over small time horizons, may vary in the long run; thus the DC bus voltage is required to reach in finite time and to track slowly varying references (set points). The motivations for a change of voltage output set point are different. For example, consider the following scenarios:

(i) A three-phase resistive load is directly connected to the generator output, and a power regulation is desired (for resistive load power regulation is equivalent to voltage regulation).

(ii) An uncontrolled AC/DC rectifier is used, for example, an ATRU, providing a DC bus voltage that needs to be regulated.

(iii) A sudden change of the rotor speed happens; then the overall rectified voltage variation has to be compensated for.

All the above cases can be dealt with by changing the field voltage of the exciter machine (and consequently of the generator).

Assuming that the generator shaft rotates at constant speed, the regulation of the generator output voltage is 


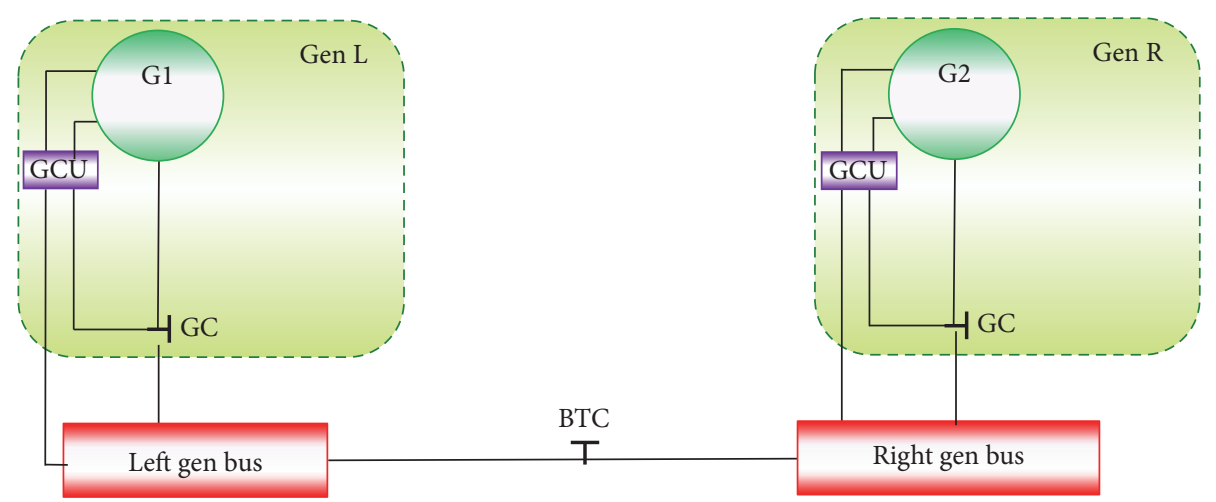

FIgURE 1: Aeronautical electrical network considered.

performed by varying the generator field windings current, by means of a Generator Control Unit (GCU). The GCU is usually based on a standard controller, that is, Proportional [3] (P) or Proportional-Integral (PI) controller [4] or lead-lag compensators [5]. However, it has been shown [6] that standard, and in general linear controllers, have a fundamental limitation: the desired set point is reached only asymptotically, theoretically in infinite time. Moreover, being based on linear control theory, most of them produce only local results on practical devices, which are usually nonlinear systems. In contrast, Variable Structure Controllers (VSC) [7] are nonlinear switching controllers known for their capabilities to reach set points in finite time. Moreover, VSC are very robust, since their design is model-free; that is, there is neither the need for an estimate of the generator parameters nor the determination of the accurate values of the parameters of the mathematical equations governing the generator behaviour. Finally, VSC works directly in nonlinear settings. VSC techniques have been recently used for controlling switched reluctance generators [8] and for standalone wound rotor synchronous generators [9]. However, the resulting control law switches between two fixed levels with a variable, unpredictable frequency, and this drawback has motivated the researchers to look for a smooth version of the VSC control, obtained by inserting an integrator at the output of the controller, so that the control action, continuous, though with a discontinuous derivative, can be implemented by standard PWM modulators. Following this approach, in [10] a permanent magnet synchronous generator system has been controlled with a second-order sliding mode controller, by using a supertwisting algorithm [11]. However, in all the previous approaches the generator system was considered as a standalone system and was modelled as a dynamic system with relative degree [12] one. On the contrary, in this paper the model of the generator, including also the filter used for rectification, has relative degree two and a twisting control algorithm is used for the first time.

A second topic addressed in this paper is the energy management on board. It is well known [13] that electric generator sizing is based on the so-called " 5 seconds" and "5 minutes" overload capability, which are a piecewise linear approximation of the true overload curve of the generator.
Roughly speaking, the generator is assumed able to withstand a large overload for the first 5 seconds, while the 5 minutes' overload level $P_{\mathrm{OL}}$ simply indicates a maximum level that the generator can supply in steady state. Obviously, if a total load is connected to the generator such that after a transient of maximum duration of $5 \mathrm{~s}$, it requires more power than the rated $P_{\mathrm{OL}}$, generator sizing has to be increased. Dually, if after $5 \mathrm{~s}$ a power level below $P_{\mathrm{OL}}$ was guaranteed, no oversize related to 5 minutes capabilities would be needed, thus reducing size and weight of the generator. This idea has been exploited in [14] for a configuration with an ideal generator and a single battery. In this paper we choose another topology. We consider a common configuration for aeronautical electrical networks, where two (or more) DC voltage busses fed by separated generators are linked via a contactor and a line, as reported in Figure 1. The contactor between the DC lines is normally open. Usually, in case of loss of a generator, the contactor is closed in order to let the active generator provide power for the loads originally assigned to the faulty generator. The idea in this paper is to extend the power transfer also to the case of generator overload. The proposed energy management strategy is referred to an architecture where two DC busses are introduced: a critical bus and a noncritical bus. The substantial difference between these busses is related to the connected loads: for the critical loads (CLs), the power demand must always be satisfied satisfying the $5 \mathrm{~s}-5 \mathrm{~min}$ criterion discussed above, without tolerating long lasting overload on the CL generator. Following the MEA approach, particularly referring to regional aircraft, a common architecture involves 4 DC busses [15], so it can be easily possible to select a couple of connected busses and concentrate CLs and NCLs, respectively. Given this, the energy management logic is based on the following steps:

(i) After the overload detection on the CLs bus, closure of the common contactor with the NCLs bus.

(ii) Increase of the NCLs bus voltage and simultaneous decrease of the CLs bus voltage, and in any case preserving the MIL-STD-704F standard [16] prescribed operating voltages for $270 \mathrm{VDC}$ systems (i.e., DC bus voltage in the range [250-280] Volts). This action permits a current transfer from the NCLs to the CLs bus. 


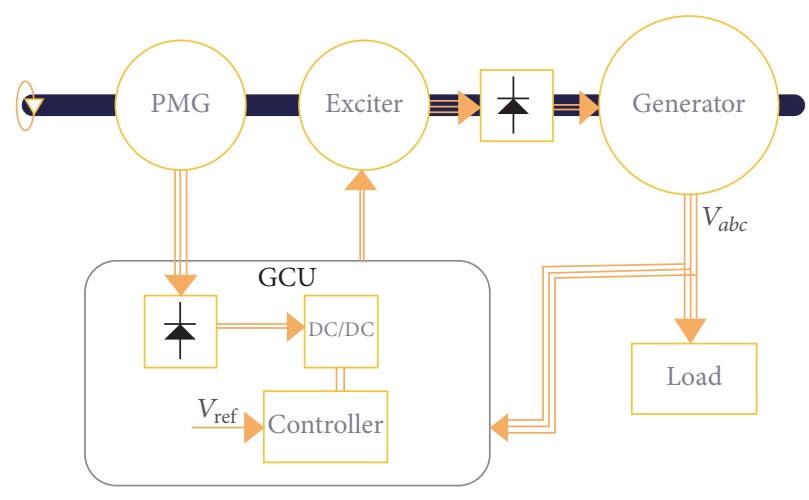

FIgURE 2: Aeronautical generator structure.

(iii) Overload management until the condition termination, associated with the regulation of the power delivered by the CLs generator at a value lower than overload. This action is obtained by iteratively looking for an optimal NCLs bus voltage, hence obtaining a proper power transfer.

(iv) Detection of the overload condition ending, restoration of the nominal voltage for the NCLs bus, and opening of the contactor between the two busses.

The paper will show how to implement this energy management strategy by relying on a robust sliding low-level control and a supervisor acting at high-level, able to coordinate the set point variation of the NCLs bus in reaction to the overload conditions of the generator associated with the CLs.

In conclusion, the innovative contribution of this paper is twofold. First, a second-order sliding manifold approach is used to control the relative degree system resulting from taking into account the rectification stage. Second, a new supervisory system is designed and tested.

\section{Electrical System Model}

Figure 2 depicts a typical three-stage brushless synchronous machine used as AC generator. The generator is a threestage brushless synchronous machine composed of the main alternator, the excitation stage, and the permanent magnet generator (PMG) $[17,18]$. The three elementary alternators are connected in cascade. The output of the PMG supplies the excitation to the exciter, where the output of the exciter is connected to the input of a rotating rectifier bridge. The DC current delivered by the rectifier bridge energizes the rotor of the main generator.

Essentially, the PMG and the exciter perform a power amplification for the field current feeding the main generator and will be neglected in this paper. The generator produces a three-phase voltage. In order to simplify the mathematical description, the Clark-Park transformations are usually used, transforming the three-phase sinusoidally varying system $(a, b, c)$ into a two-phase stationary set $(d, q)$ [19]. With this simplification, using the two components of the stator currents $\left(i_{d}, i_{q}\right)$ and the field current $i_{F}$ as state variable (i.e., $\left.x=\left(i_{d}, i_{q}, i_{F}\right)^{T}\right)$ the mathematical model of the generator is [9]

$$
\mathbf{L} \dot{x}=\left(\begin{array}{ccc}
-R_{s} & \omega L_{s} & 0 \\
-\omega L_{s} & -R_{s} & -\omega L_{m} \\
0 & 0 & -R_{F}
\end{array}\right) x+\left(\begin{array}{c}
v_{d} \\
v_{q} \\
v_{F}
\end{array}\right)
$$

where

$$
\mathbf{L}=\left(\begin{array}{ccc}
L_{s} & 0 & L_{m} \\
0 & L_{s} & 0 \\
L_{m} & 0 & L_{F}
\end{array}\right)
$$

and

(i) $\omega$ is electrical rotor speed (i.e., $p$ times the rotor angular speed, where $p$ is the number of polar pairs of the machine);

(ii) $v_{d}, v_{q}$ are armature $d$ - and $q$-axis voltage, respectively;

(iii) $v_{F}$ is field winding voltage;

(iv) $R_{s}, R_{F}$ are stator and field resistance, respectively;

(v) $L_{s}, L_{m}$ are stator and magnetization inductance, respectively;

(vi) $L_{F}$ is field inductance.

The relationship between $v_{d}, v_{q}, i_{d}$, and $i_{q}$ depends on the load fed by the generator. The output voltage of the generator is connected to the $\mathrm{AC} / \mathrm{DC}$ rectifier bridge, which introduces nonlinearities to the system, due to the presence of the diodes (see also [20]). However, harmonic analysis of the voltage waveforms on the AC side shows that the first harmonic is largely representative of the voltage shape.

To model the rectifier, detailed descriptions based on a hybrid model of the process have been proposed. Specifically, for each diode commutation one state of a state machine has been considered [21]. This description, though accurate and rigorous from the modelling point of view, requires sophisticated mathematical tools to assess the stability of the feedback control law. However, since we are only interested in situations where the DC voltage is constant (or slowly 


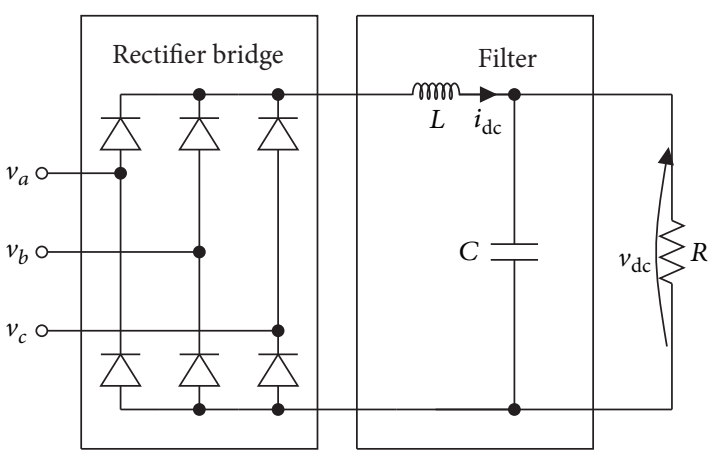

FIGURE 3: Generator output rectifier and filter.

varying) and the control design is model-free, a simple approach to the model of the uncontrolled rectifier, based on an average model computed by equating the power at the input and at the output of the rectifier [22] (i.e., assuming lossless diode bridge) is adopted. With this approach the average value of the rectified voltage $\bar{v}_{\mathrm{dc}}$ and the average values of the $d, q$ generator voltages $\left(\bar{v}_{d}, \bar{v}_{q}\right)$ are related by

$$
\bar{v}_{\mathrm{dc}}=k_{v} \sqrt{\overline{\bar{v}}_{d}^{2}+\bar{v}_{q}^{2}}
$$

for a suitable constant $k_{v}$ [22] depending on the load. The same argument applied to the current shows that an analogous relation holds for the average value of the rectified current $\bar{i}_{\mathrm{dc}}$ and the average values of the $d, q$ generator currents $\left(\bar{i}_{d}, \bar{i}_{q}\right)$; that is,

$$
\bar{i}_{\mathrm{dc}}=k_{i} \sqrt{\bar{i}_{d}^{2}+\bar{i}_{q}^{2}}
$$

for a suitable constant $k_{i}$. In order to reduce the ripple on the DC side, an LC filter is considered, as shown in Figure 3.

In particular, the capacitor is chosen to reduce the ripple, while the inductor is used to adjust the power factor of the load. A simple calculation shows that by choosing

$$
L=\frac{1}{C \omega^{2}}
$$

the load appears as purely resistive (as long as the first harmonics are concerned). With this approximate hypothesis, the relationship between stator current and voltages is

$$
\left(\begin{array}{c}
v_{d} \\
v_{q}
\end{array}\right)=-R_{L}\left(\begin{array}{l}
i_{d} \\
i_{q}
\end{array}\right)
$$

for a given "equivalent" load $R_{L}$, and (1) becomes

$$
\mathbf{L} \dot{x}=\left(\begin{array}{ccc}
-R_{s}^{\prime} & \omega L_{s} & 0 \\
-\omega L_{s} & -R_{s}^{\prime} & -\omega L_{m} \\
0 & 0 & -R_{F}
\end{array}\right) x+\left(\begin{array}{c}
0 \\
0 \\
v_{F}
\end{array}\right),
$$

where $R_{s}^{\prime}=R_{s}+R_{L}$. The above description is exactly the one obtained in [9] in the case of standalone generator. Note that this description is valid on the generator side, that is, before the rectifier bridge.

In the sequel, due to the large values for the capacitor $C$ and the velocity $\omega$ the presence of the inductor $L$ will be neglected. This assumption will be reflected in a small modelling error that will be counteracted by the robustness capability of the controller.

\section{Control of the Generator in Sliding Mode}

Traditionally, aeronautical generators such as the one depicted in Figure 2 are regulated in their output voltage by using a GCU (Generator Control Unit), which embeds a DC/DC converter managed by a PI controller. This classical solution guarantees that a generator is able to keep the 270 VDC reference and reject common disturbances. However, for the scopes of energy management, this approach becomes unsatisfactory due to additional requirements related to the fast tracking of a time-varying reference and the need for high accuracy in reference tracking. For this reason, we investigate the use of sliding mode control for enhancing the control stage performances. Sliding manifold and related sliding mode approaches have been used for years in control applications. There are many reasons for the successful application of these strategies, but the main one is their ability to deal with the control of nonlinear and uncertain plants. In fact, sliding mode controllers are celebrated for their strong robustness properties, with respect to unmodelled dynamics and exogenous unknown disturbances. Obviously, there is a price to pay for the high accurateness and the strong robustness properties: typically, sliding manifold strategies, both in the high-gain [23] and in the discontinuous control version [7], require usually large controller bandwidth. Reducing the controller bandwidth for easy implementation (e.g., using converters with relatively low switching frequency) reduces closed-loop system performances; hence if this bandwidth-performance tradeoff is considered too conservative different approaches have to be considered (e.g., adaptive control [24-26]). However their integration in supervisory control structures is still to be investigated and the usage in systems with multiple busses is complex.

Basically, the idea behind sliding mode is very simple: it is sufficient to formulate control objectives and performances in terms of a suitable sliding manifold $\Sigma$ defined by the solution of a (set of) equation(s) $\sigma=0$ so that if the if the system state time evolution is forced to belong to the manifold the required performances are automatically met. Obviously, in practical implementation of sliding control the state of the system must be driven to the sliding manifold and kept on it (i.e., a stable reaching phase must be guaranteed) and the motion on the manifold must be confined to bounded subsets (i.e., stability of the motion on the manifold must holds). Specifically, the so-called equivalent control is obtained by derivation (see [7]) or successive derivation (see [23]) of the sliding function $\sigma$. The equivalent control is what is really needed to satisfy design specs but cannot be directly implemented, since it would require a perfect knowledge of the system (i.e., perfect modelling and zero uncertainties on 
the parameters), which is clearly unrealistic. Thus, a highgain or a switching implementation of the control law is designed so that a control action whose average coincides with the equivalent control is obtained.

Since the control objective is to steer the voltage on the DC bus $v_{\mathrm{dc}}$ towards a reference value $V_{\text {ref }}$, thus, consider the sliding function

$$
\sigma=v_{\mathrm{dc}}-V_{\text {ref }}
$$

In order to define the control strategy, we need the time derivatives of the sliding function. Note that, from Figure 3, the DC voltage after rectification (and neglecting the inductor $L)$ is

$$
\tau \dot{v}_{\mathrm{dc}}=-v_{\mathrm{dc}}+R i_{\mathrm{dc}},
$$

where $\tau=R C$. Hence the derivative of the sliding function is

$$
\dot{\sigma}=-\frac{v_{\mathrm{dc}}}{\tau}+\frac{R i_{\mathrm{dc}}}{\tau}-\frac{d V_{\mathrm{ref}}}{d t} .
$$

In the above derivation we have considered a generic reference voltage, not necessarily constant. Note that the control input $v_{F}$ does not appear in the first derivative of $\sigma$, showing that the relative degree of the generator-rectifier-filter with input $v_{F}$ and output function $\sigma$ is larger than one [27]. In order to derive again, the expression for the derivative of $i_{\mathrm{dc}}$ has to be computed. Approximatively, the bus current $i_{\mathrm{dc}}$ is related to the generator currents by (4). Again, we stress that this is a crude approximation, whose validity will be assessed by the strong robustness properties of the sliding mode approach. Then, it is not hard to show that, deriving twice $\sigma$, the control variable $v_{F}$ appears and in particular

$$
\ddot{\sigma}=\varphi(x, t)+\rho \frac{i_{d}}{i_{\mathrm{dc}}} v_{F},
$$

where $\varphi(x, t)$ is function not depending on $v_{F}$ that is assumed bounded, $|\varphi(x, t)| \leq \Phi$ for some known constant $\Phi>0$, and $\rho>0$ is a constant.

Since the relative degree of the system with output function $\sigma$ is two, a second-order sliding mode strategy [28] has to be employed. In this paper we proposed a new control strategy.

$$
v_{F}=\operatorname{sign}\left(i_{\mathrm{dc}}\right) \operatorname{sign}\left(i_{d}\right)\left(-M_{0} \operatorname{sign}(\sigma)-M_{1} \operatorname{sign}(\dot{\sigma})\right)
$$

with $M_{0}>0$ and $M_{1}>\Phi / \rho+M_{0}\left(1 / \rho-I_{d}^{-} / I_{\mathrm{dc}}^{+}\right)$, where $I_{d}^{-}<\left|i_{d}\right|$ and $I_{\mathrm{dc}}^{+}>\left|i_{\mathrm{dc}}\right|$ are an estimate of the lowest and largest values for the DC current and the $d$-component of the generator current, respectively. It is possible to show that the rationale for this control law is the same as the wellknown twisting control algorithm [28]. Specifically, selecting a positive definite Lyapunov function

$$
V=\sqrt{\frac{1}{2} \dot{\sigma}^{2}+M_{0}|\sigma|}
$$

results into the time derivative bounded as

$$
\dot{V} \leq-\left[M_{1}-\frac{\Phi}{\rho}+M_{0}\left(\frac{1}{\rho}-\frac{I_{d}^{-}}{I_{\mathrm{dc}}^{+}}\right)\right] \frac{|\dot{s}|}{V} .
$$

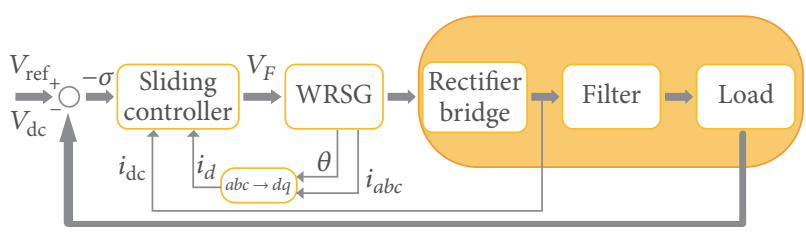

FIGURE 4: Sliding control for a WRSG.

That is an equation with exactly the same form as the Lyapunov function in [6, Chapter 3.6.2]. From this point on the proof of stability follows exactly the same steps in [6, Chapter 3.6.2]. It stabilises the closed-loop system and assures convergence to a neighbourhood of $v_{\mathrm{dc}}$ to $V_{\text {ref }}$ in finite time. Note that only a very rough estimation of the parameters $\Phi$ and $\rho$ is needed, and this motivates the strong robustness properties of the sliding mode control: basically, it is a modelfree approach, and the details of the model can be ignored. The only information needed is the relative degree. Moreover, as in any twisting algorithm, the derivative of the sliding function has to be computed or estimated.

The overall scheme for the proposed sliding mode regulator for controlling the Wound Rotor Starter Generator (WRSG) is given in Figure 4.

The three-phase output voltages of the generator are transformed in their $(d, q)$ components by using the Clarke transformation. Then the sliding function (8) is computed, along with its (approximate) time derivative. Different approached can be used, for example, high-pass filter, numerical derivation, or Levant finite-time differentiator [29]. Next, control law (12) is computed. In practical applications, the field voltage will in turn be produced by using a DC/DC converter controlled by a suitable strategy (e.g., PWM, sliding mode [30] or high-gain [31]), but in this paper we will not address this issue.

A schematic of the detailed simulator in SABER for the control of a single generator is shown in Figure 5.

Up to now we have considered a single generator controlled by one controller. It is possible to consider different generators interconnected, each controlled by its own controller, as shown in Figure 1 in the case of two generators. In this case it is important to design a high-level controller (supervisor) to coordinate the action of each sliding controller.

\section{Supervisory System for Energy Management}

A supervisor can be defined as a controller at higher hierarchical level with respect to the reference tracking control. Several well-known examples can be found in process control (e.g., SCADA systems [32] or Petri Nets supervisors [33]), while in aeronautics the introduction of supervisory systems is more recent, especially when referring to energy management scopes $[34,35]$. The objective of a supervisor can vary depending on the application requirements; in this case, our supervisory system can be described as an automaton that evolves between three states depending on the overload 


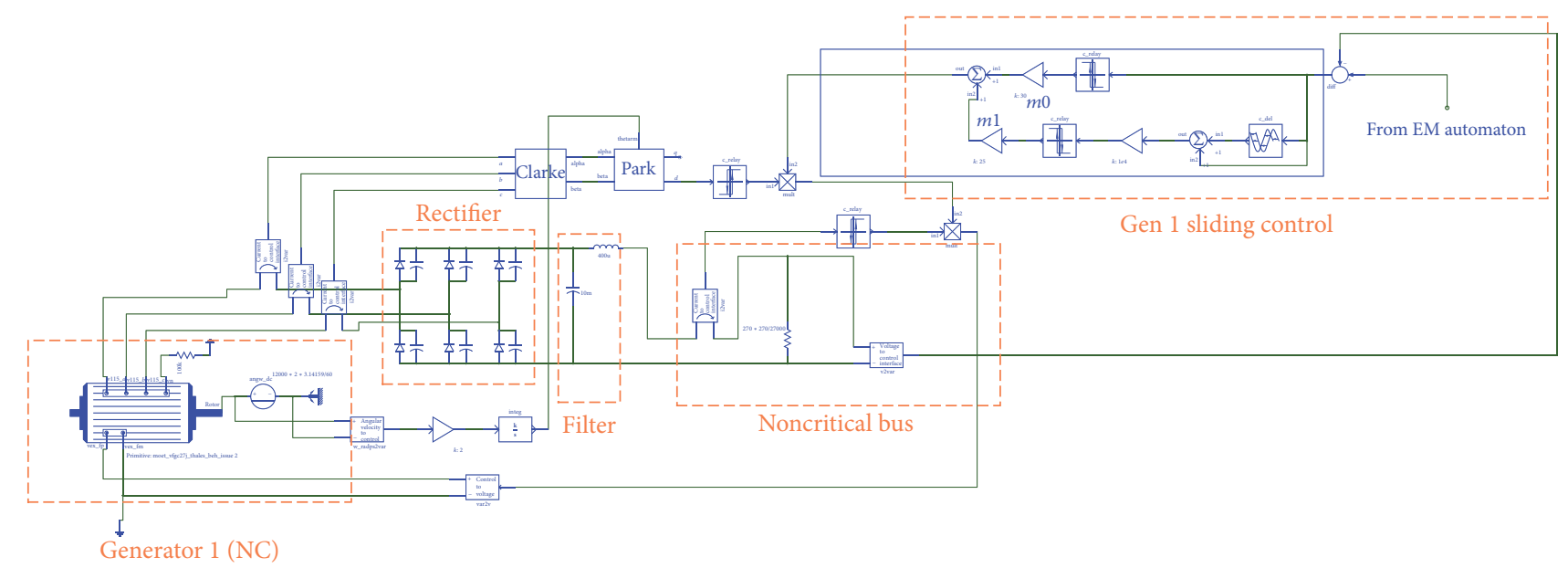

FIGURE 5: SABER schematic for single bus.

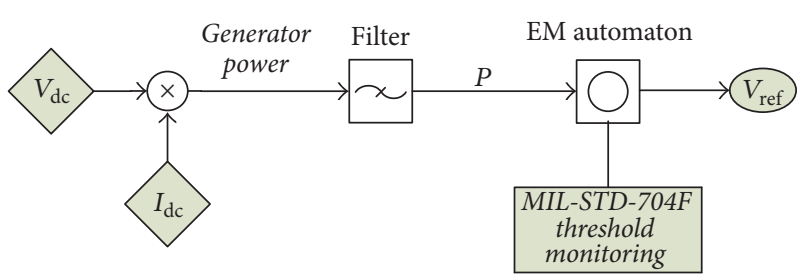

FIGURE 6: Energy management system.

condition, consequently providing a variable set point for a low-level controller, that is, $V_{\text {ref }}$ in Figure 4.

Our scenario considers two busses, each fed by its own generator. One of the two busses is the "critical" bus, as mentioned in the Introduction, while the other is the "noncritical" bus. The key idea is that in the case of overload of the critical bus, the noncritical one is called for, helping the former. This is accomplished by increasing the voltage of the noncritical bus, while decreasing the voltage on the critical one, so that power can flow from the noncritical to the critical bus through the contactor and the connecting line. The flow of power is regulated by a droop controllike [36] strategy; namely, the voltage of the NCL generator is linearly increased and the voltage of the CL generator decreased (both at the same rate), until the power supplied from the NCL to the CL is enough to clear the overload. At this point, both references stop varying. The above strategy is implemented as shown in Figure 6. First the power on CL side is estimated by filtering the product of DC voltage and current of the CL generator. The estimated power is processed by an automaton that produces the correct voltage reference for both busses. Note that the automaton is aware of the constraints on minimum and maximum voltage prescribed by the MIL standard and stops increasing (or decreasing) the references if these constraints are going to be violated.

Next, if the cause of overload ends (e.g., because some loads are disconnected from the critical bus) the initial condition of equal references on both busses is restored.

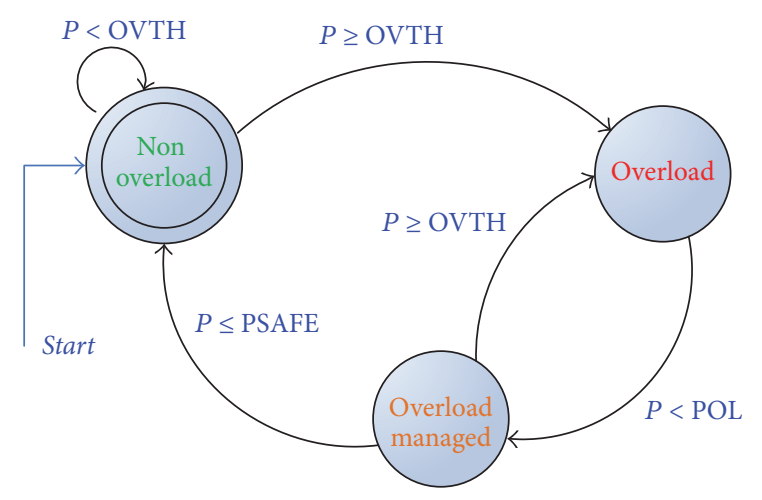

FIgURE 7: Energy management automaton.

The energy management automaton discussed so far is detailed in Figure 7.

Three quantities are here defined:

(i) OVTH: the overload detection threshold, here defined as equal to $30 \mathrm{~kW}$;

(ii) PSAFE: the overload clearing value, here defined as equal to $28 \mathrm{~kW}$;

(iii) $P_{\mathrm{OL}}$ : the lower overload status regulation value, here defined as equal to $29 \mathrm{~kW}$

The energy management logic here reported receives as input $P$, that is, a filtered estimate of the power delivered by the CLs generator, and produces as output logical conditions to manage the overload. The automaton starts in state "Nonoverload" and remains there until an overload condition is detected; for example, $P \geq \mathrm{OVTH}$. Then, the "Overload" state is entered and the voltage references are changed by decreasing linearly the CL voltage reference with slope $-k$ while increasing the NCL voltage with slope $k$. Here $k>0$ is a prescribed slope that has to be selected by trading off a quick power transfer (which requires a large bandwidth controller for $v_{F}$ ) versus a 
TABLE 1: Generator and filter parameters.

\begin{tabular}{llc}
\hline Name & Description & Value \\
\hline$R_{S}$ & Stator resistance & $22.2 \mathrm{~m} \Omega$ \\
$R_{F}$ & Field resistance & $340 \mathrm{~m} \Omega$ \\
$L_{S}$ & Stator inductance & $18.2 \mu \mathrm{H}$ \\
$L_{m}$ & Magnetization inductance & $0.85 \mathrm{mH}$ \\
$L_{F}$ & Field inductance & $4.76 \mathrm{mH}$ \\
$L$ & Filter inductance & $0.4 \mathrm{mH}$ \\
$C$ & Filter capacitance & $10 \mathrm{mF}$ \\
\hline
\end{tabular}

TABLE 2: Controller and supervisor parameters.

\begin{tabular}{lcc}
\hline Name & Description & Value \\
\hline$M_{0}$ & Controller parameter & 30 \\
$M_{1}$ & - & 25 \\
$k$ & Supervisor parameter & 10 \\
\hline
\end{tabular}

slow transfer (which contrasts with the desired $5 \mathrm{~s}$ recovery capability). A simulation campaign is useful in the selection.

If the power injected in the CL side is enough to clear the overload, the references are kept constant and the state "Overload Management" is entered. In order to avoid chattering, a threshold $P_{\mathrm{OL}}$ is considered, with $P_{\mathrm{OL}}<\mathrm{OVTH}$.

Finally, if the required power falls below a "safety" level, PSAFE, the automaton considers the emergency situation ended and resets the original voltage levels and disconnects the two busses.

\section{Simulation Results}

The proposed sliding mode control and associated energy management strategy for aeronautical generators have been tested in a detailed SABER simulation environment. Generator parameters with typical values in aeronautic applications are reported in Table 1, while the controller parameters are in Table 2.

A first set of simulations has been carried out referring to a nonsupervised control and a single generator, in order to test the effectiveness of the sliding mode control strategy in tracking different desired voltages. Specifically, a stepwise changing reference for the DC bus voltage has been imposed, with set points $270 \mathrm{~V}, 250 \mathrm{~V}$, and $280 \mathrm{~V}$ at the initial time, at $t=0.2 \mathrm{~s}$ and at $t=0.4 \mathrm{~s}$, respectively. A pure resistive load is connected to the DC bus, absorbing $27 \mathrm{~kW}$ at nominal voltage $270 \mathrm{~V}$. The results obtained using the above control law are shown in Figure 8, where the DC voltage after rectification is shown (in blue) and compared with the desired set point (in green). The simulations show that the generator, after a quick reaching phase, follows accurately the reference voltages in finite time. In Figure 9 the control signal, that is, the commanded generator field voltage, is shown in a short time interval. It is apparent that the twisting algorithm imposes only four voltage levels.

Next, the robustness of the low-level controller is shown. In a second set of simulations, a constant reference is imposed and the load is varied abruptly from the nominal values

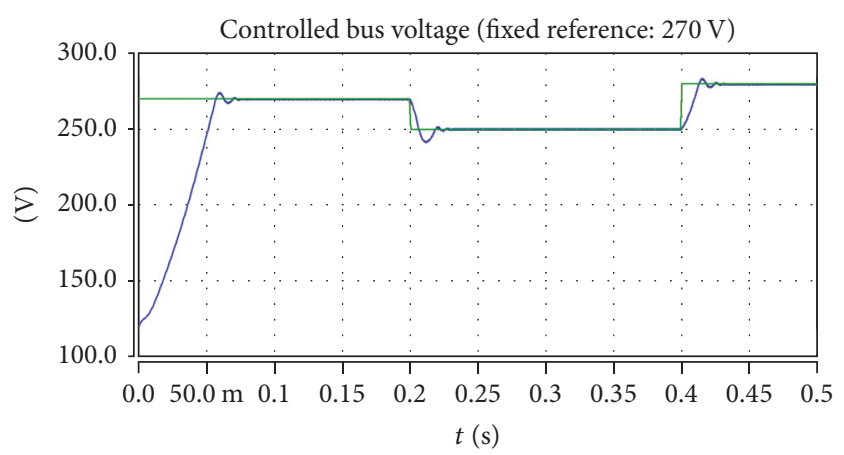

$$
\begin{aligned}
& (\mathrm{V}): t(\mathrm{~s}) \\
& - \text { Bus voltage } \\
& - \text { Bus voltage reference }
\end{aligned}
$$

Figure 8: Simulation results for low-level sliding control with varying reference.

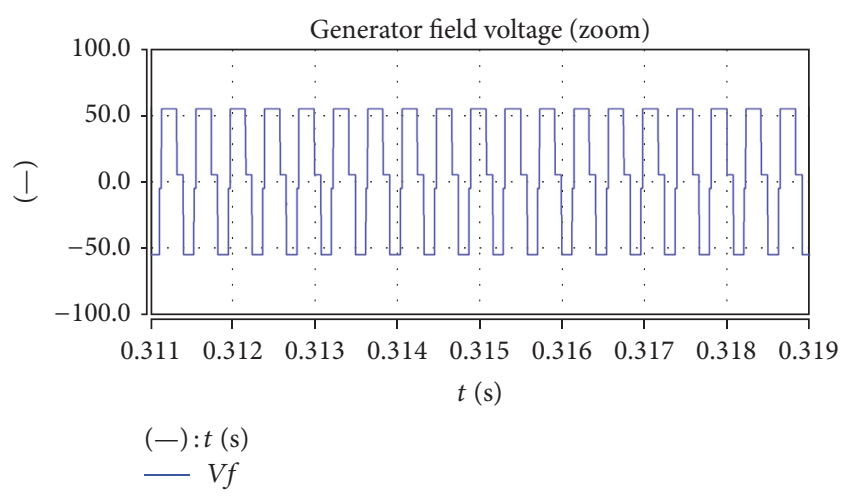

Figure 9: Generator field voltage (detail).

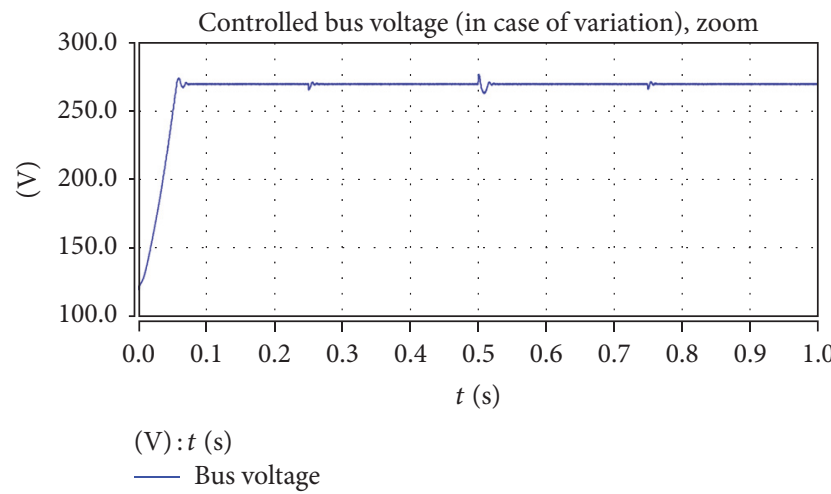

FIGURE 10: Simulation results for low-level sliding control with varying load.

$27 \mathrm{~kW}$ to $33 \mathrm{~kW}$ to $21 \mathrm{~kW}$ and finally back to the initial value $27 \mathrm{~kW}$. The results are presented in Figure 10, showing the strong robustness properties of the sliding mode strategy. Basically, the controller is able to counteract the disturbance and to quickly recover the prescribed voltage reference. A zoom around the first load change is shown in Figure 11.

The next set of simulations are devoted to check the effectiveness of the proposed energy management strategy. In this case a different, more complex simulation test bench 


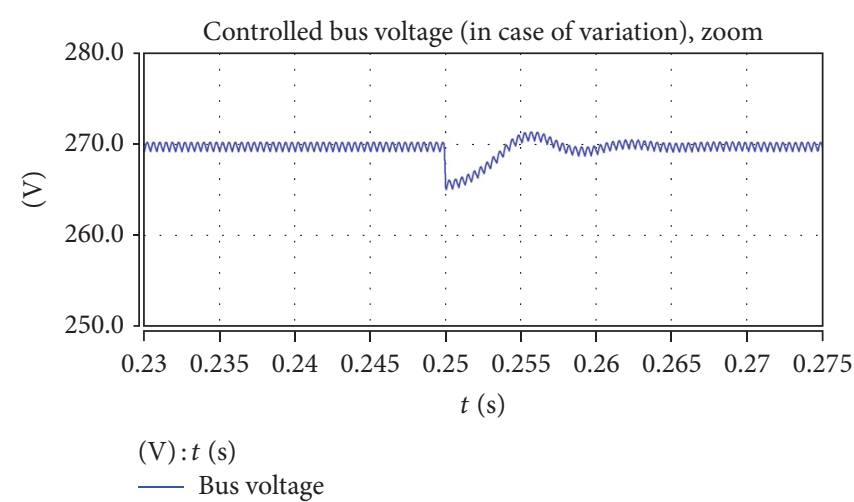

FIGURE 11: Simulation results for low-level sliding control with varying load (zoom).
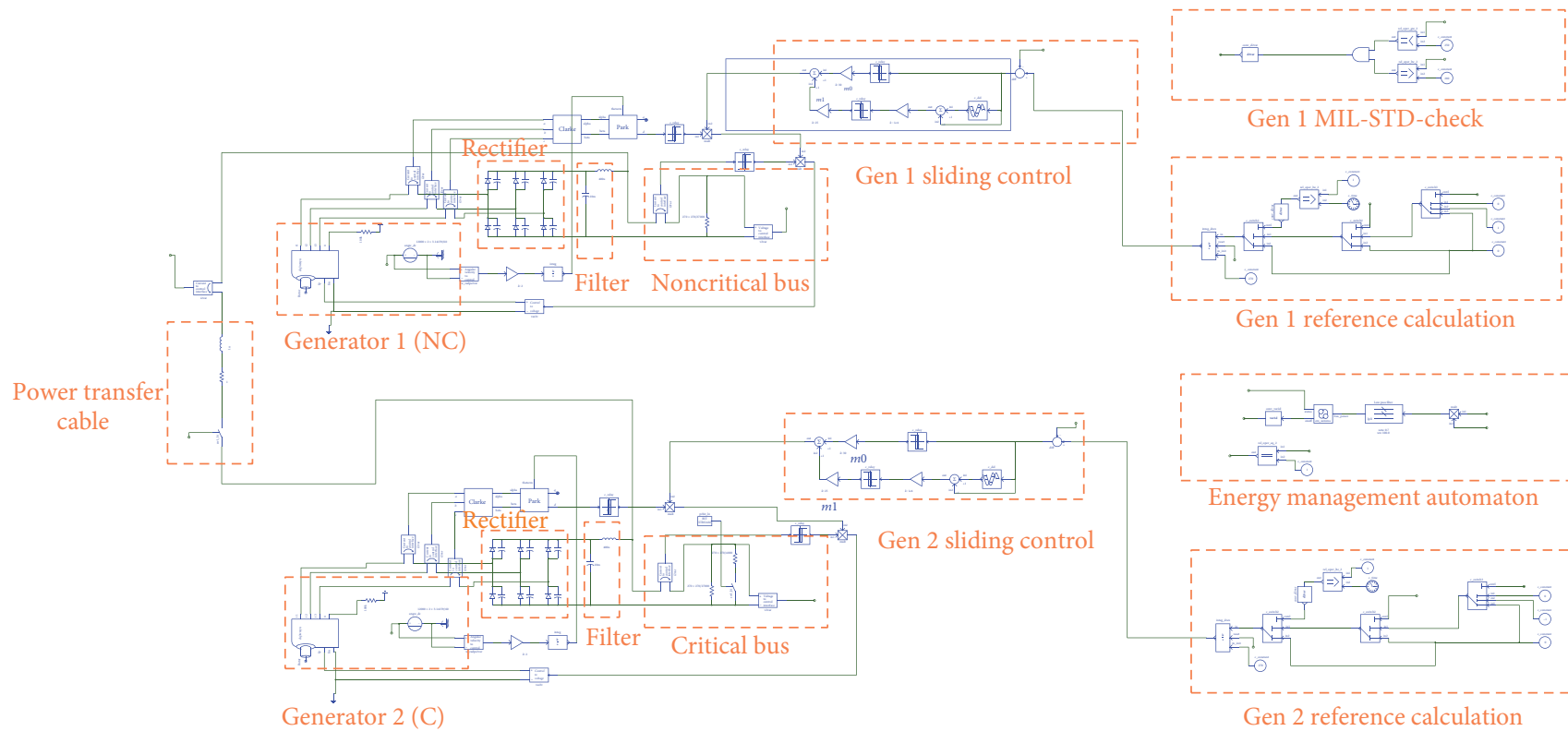

Gen 1 reference calculation
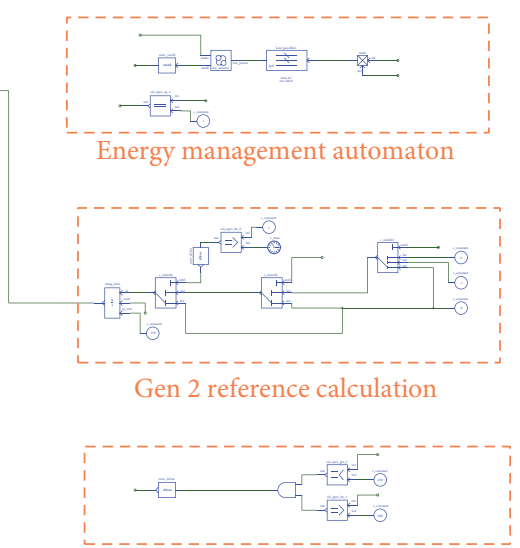

Gen 2 MIL-STD-check

FIGURE 12: SABER schematic for the double bus control.

is used, encompassing two generators. The generators are joined by a power cable, modelled as a transmission line with resistance $1 \Omega$ and inductance $10 \mu \mathrm{H}$. The SABER schematic is shown in Figure 12.

As stated above, a generator overload level OVTH = $30 \mathrm{~kW}$ has been defined, and different loads have been considered on the critical bus. A first scenario is presented in Figure 13. Starting from a steady state condition where the power delivered by the generator is $27 \mathrm{~kW}$, as shown in Figure 13(b); hence, below OVTH, an additional load has been inserted at $t=2.5 \mathrm{~s}$, asking for power exceeding OVTH. The energy management algorithm reacts to the overload condition by decreasing the DC critical bus voltage, as in Figure 13(c), while increasing the noncritical bus voltage, as in Figure 13(d), until the power supplied by the critical generator decreases to a value lower than $P_{\mathrm{OL}}$. Note that this temporary degradation does not impact the performances of the loads connected to the DC bus, because the DC bus voltage is kept within the margins prescribed in [16]. Moreover, the power degradation occurs within $5 \mathrm{~s}$ from the overload detection, hence in line with the energy management objectives. Finally, at $t=5 \mathrm{~s}$, the additional load is removed and the generator overload condition is cleared. For this reason, both the critical and the noncritical bus voltages are restored to the nominal $270 \mathrm{~V}$ condition by the energy management system. The current injected by the noncritical bus to the critical bus is shown in Figure 13(a) and the state machine timing diagram in Figure 13(e).

Next, a second scenario for the configuration is considered and the results are presented in Figure 14. At the 


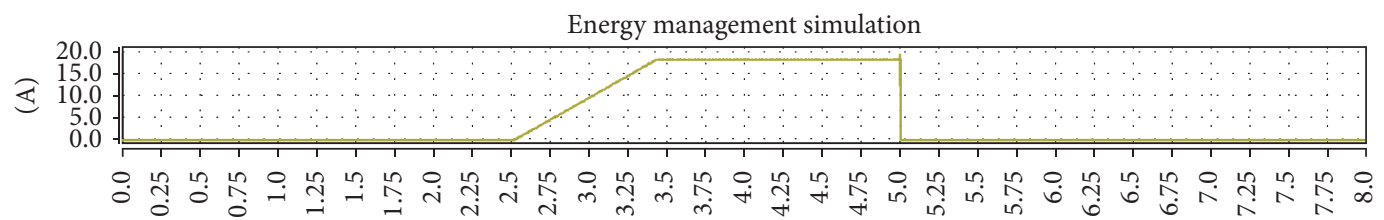

$t(\mathrm{~s})$

(A) : $t(\mathrm{~s})$

- Current bus $\mathrm{NC} \rightarrow$ bus $C$

(a)

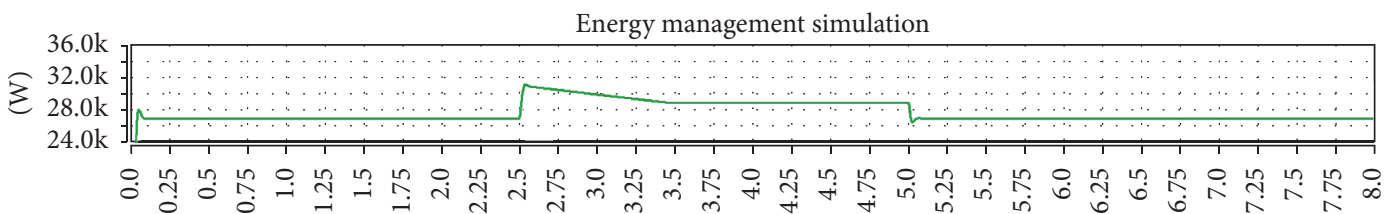

$t$ (s)

$(\mathrm{W}): t(\mathrm{~s})$

Critical bus power

(b)

Energy management simulation

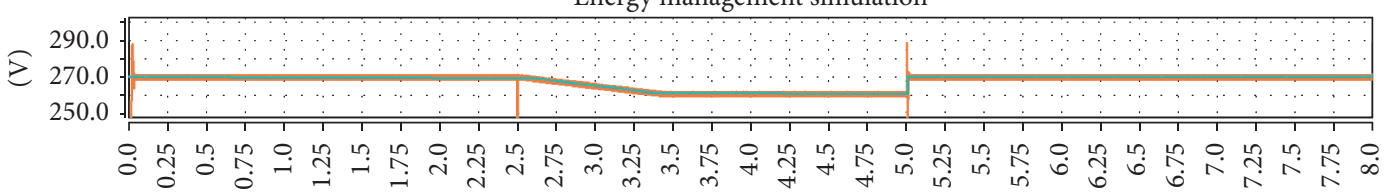

$(\mathrm{V}): t(\mathrm{~s})$

$\checkmark$ bus critical

- $V$ bus critical ref

(c)

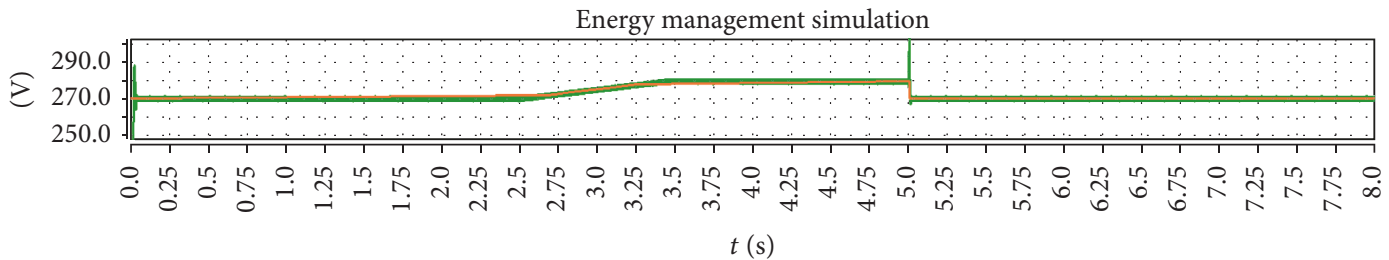

$(\mathrm{V}): t(\mathrm{~s})$

- $V$ bus noncritical

_ $V$ bus noncritical ref

(d)

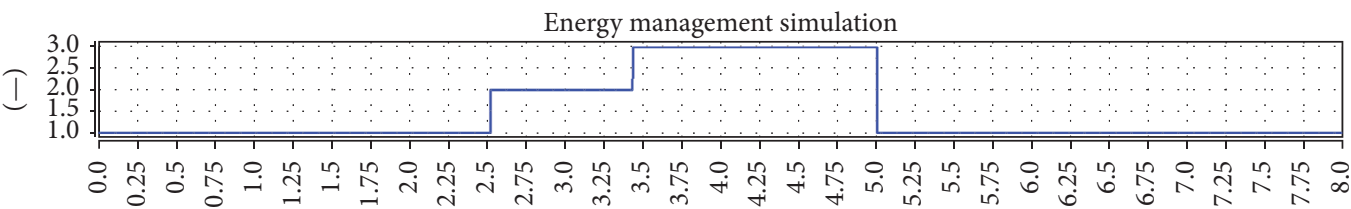

$t(\mathrm{~s})$

$(-): t(\mathrm{~s})$

- EM automaton status

(e)

FIGURE 13: Double bus control, Scenario 1. 


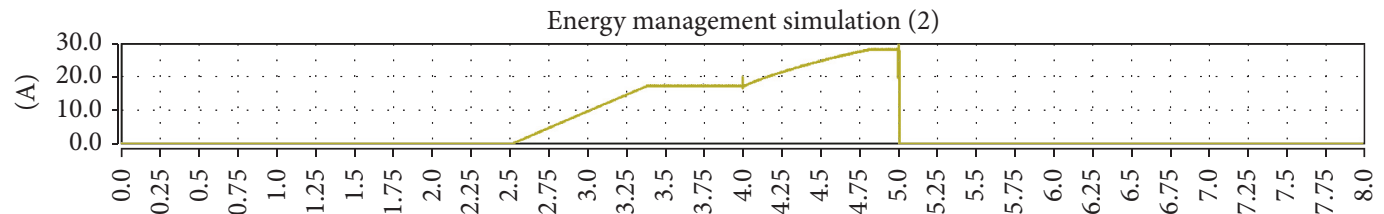

$t(\mathrm{~s})$

(A) $: t(\mathrm{~s})$

$\longrightarrow$ Current bus $\mathrm{NC} \rightarrow$ current bus $C$

(a)

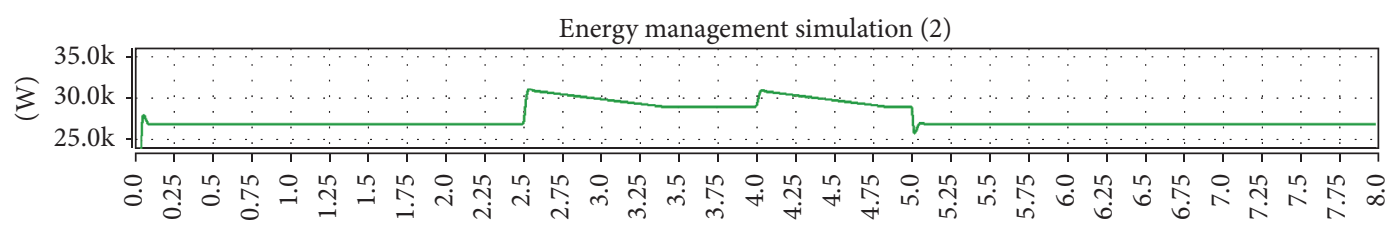

$t(\mathrm{~s})$

$(\mathrm{W}): t(\mathrm{~s})$

— Critical bus power

(b)

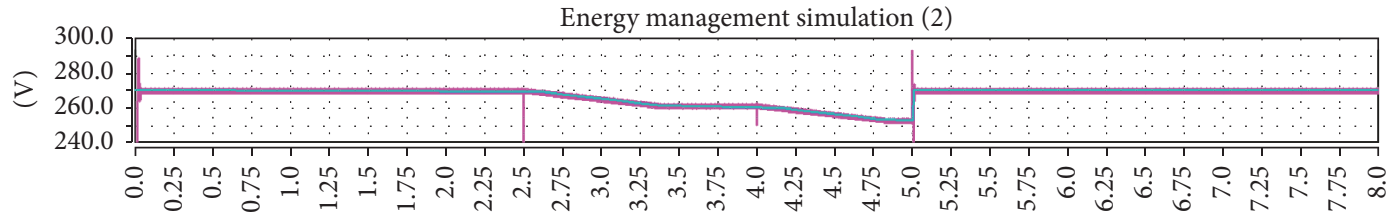

$t(\mathrm{~s})$

$(\mathrm{V}): t(\mathrm{~s})$

$\checkmark$ bus critical

- $V$ bus critical ref

(c)

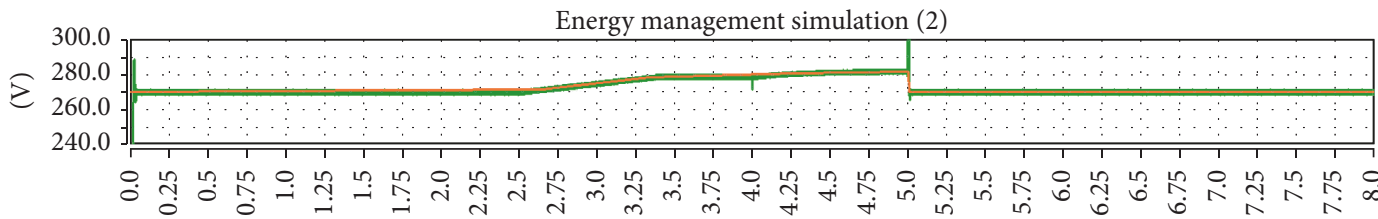

$t(\mathrm{~s})$

$(\mathrm{V}): t(\mathrm{~s})$

- $V$ bus noncritical

- $V$ bus noncritical ref

(d)

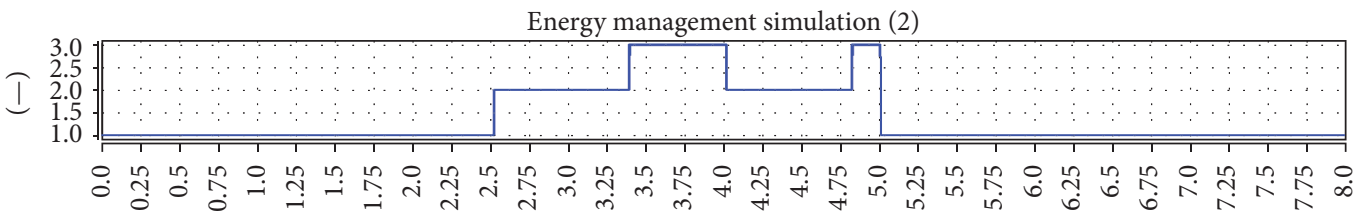

$t(\mathrm{~s})$

$(-): t(\mathrm{~s})$

_ EM automaton status

(e)

FIgURE 14: Double bus control, Scenario 2. 
beginning this scenario coincides with the previous one, until time $t=4 \mathrm{~s}$, when in both scenarios the automaton is in the state "Overload Managed." Different from the first scenario, now a new load is introduced that causes another overload (i.e., $P>\mathrm{OVTH}$ ) to happen. Then the supervisor goes automatically back to state "Overload," as shown in Figure 14(e), and the voltage reference on the critical bus is decreased again, while increasing the voltage on the noncritical bus, and more current is supplied from the noncritical bus, as shown in Figure 14(a). At $t=4.8 \mathrm{~s}$ the overload is managed (the bus power in Figure 14(b) decreases to $P_{\mathrm{OL}}$ ) and, finally, at $t=5 \mathrm{~s}$ the total load is restored to its initial value, so the overload is cleared and the automaton goes back to the initial state; hence the references for the two busses are restored to $270 \mathrm{~V}$.

\section{Conclusions}

In this paper, a novel control strategy for aeronautical electrical generators has been presented and used in the context of an innovative energy management strategy, adopted for obtaining a power transfer between two generators on different busses connected by a bus contactor. First, the system structure has been described, as composed of two main threephase generators, with their excitation devices. The output voltages of the generators are rectified by uncontrolled rectifiers and produce the main DC bus voltages for aeronautical electrical networks. Two busses are considered as a minimal configuration for discussing possible energy management strategies. One of the paper pillars is the introduction of a sliding mode controller for the exciter, controlling the rotor field of the synchronous generator and indirectly the DC bus voltage. The control strategy has been used as a base for obtaining an effective energy management logic implementation, aiming at facing the generator overloads automatically. A supervisor based on automata is also presented to manage overloads on the critical bus. Different possible scenarios are considered and analysed. Detailed simulation results in SABER simulation software show the effectiveness of the proposed approach and constitute a solid base for subsequent experimental validation of the proposed energy management strategy and associated sliding mode control.

\section{Conflicts of Interest}

The authors declare that there are no conflicts of interest regarding the publication of this paper.

\section{References}

[1] A. Emadi and M. Ehsani, "Aircraft power systems: technology, state of the art, and future trends," IEEE Aerospace and Electronic Systems Magazine, vol. 15, no. 1, pp. 28-32, 2000.

[2] A. Cavallo, C. Natale, S. Pirozzi, and C. Visone, "Limit cycles in control systems employing smart actuators with hysteresis," IEEE/ASME Transactions on Mechatronics, vol. 10, no. 2, pp. 172180, 2005.

[3] C. Cossar and T. Sawata, "Microprocessor controlled dc power supply for the generator control unit of a future aircraft generator with a wide operating speed range," in Proceedings of the
Second International Conference on Power Electronics, Machines and Drives (PEMD '04), vol. 2, pp. 458-463, Edinburgh, UK, 2004.

[4] J. Li, J. Gao, Y. Yang, C. Zhang, W. Li, and X. Zhang, "Digital generator control unit for a variable frequency synchronous generator," in Proceedings of the 19th International Conference on Electrical Machines and Systems (ICEMS '16), pp. 1-6, 2016.

[5] S. Rosado, X. Ma, G. Francis, F. Wang, and D. Boroyevich, "Model-based digital generator control unit for a variable frequency synchronous generator with brushless exciter," IEEE Transactions on Energy Conversion, vol. 23, no. 1, pp. 42-52, 2008.

[6] V. Utkin, J. Guldner, and J. Shi, Sliding Mode Control in ElectroMechanical Systems, CRC Press, 2nd edition, 2009.

[7] V. Utkin, Sliding Modes and Their Application in Variable Structure Systems, Imported Publications, Incorporated, 1978.

[8] H. Chen, X. Wang, and J. J. Gu, "Sliding mode control of switched reluctance linear generator system," in Proceedings of the 2009 IEEE International Conference on Networking, Sensing and Control, ICNSC 2009, pp. 779-782, jpn, March 2009.

[9] R. S. Muñoz-Aguilar, A. Dòria-Cerezo, E. Fossas, and R. Cardoner, "Sliding mode control of a stand-alone wound rotor synchronous generator," IEEE Transactions on Industrial Electronics, vol. 58, no. 10, pp. 4888-4897, 2011.

[10] F. Valenciaga and R. D. Fernandez, "Multiple-input-multipleoutput high-order sliding mode control for a permanent magnet synchronous generator wind-based system with grid support capabilities," IET Renewable Power Generation, vol. 9, no. 8, pp. 925-934, 2015.

[11] A. Levant, "Higher-order sliding modes, differentiation and output-feedback control," International Journal of Control, vol. 76, no. 9-10, pp. 924-941, 2003.

[12] J. Huang, Nonlinear Output Regulation: Theory and Applications, vol. 8 of Advances in Design and Control, Society for Industrial and Applied Mathematics, Philadelphia, Pa, USA, 2004.

[13] B. Guida and A. Cavallo, "A Petri net application for energy management in aeronautical networks," in Proceedings of the IEEE 18th International Conference on Emerging Technologies and Factory Automation (ETFA '13), September 2013.

[14] A. Cavallo, G. Canciello, and B. Guida, "Supervised control of buck-boost converters for aeronautical applications," Automatica, vol. 83, pp. 73-80, 2017.

[15] B. Guida and A. Cavallo, "Intelligent power regulation using innovative modules for energy supervision," in Proceedings of the International Conference on Electrical Systems for Aircraft, Railway, Ship Propulsion and Road Vehicles, ESARS 2015, deu, March 2015.

[16] "Mil-std-704f aircraft electric power characteristics," standard, U.S. Department of Defense, Mar, 2004.

[17] A. Hoffman, "Advanced secondary power system for transport aircraft," NASA technical paper, National Aeronautics and Space Administration, Scientific and Technical Information Branch, 1985.

[18] "Aviation maintenance technician handbook - airframe," standard, Federal Aviation Administration, U.S. Department of Transportation, 2012.

[19] P. C. Krause, O. Wasynczuk, and S. D. Sudhoff, Analysis of Electric Machinery and Drive Systems, IEEE Press power engineering series, Wiley, 2002. 
[20] N. Mohan, T. Undeland, and W. Robbins, Power Electronics. Wiley, 1989.

[21] A. Tantawy, X. Koutsoukos, and G. Biswas, "Aircraft AC generators: Hybrid system modeling and simulation," in Proceedings of the 2008 International Conference on Prognostics and Health Management, PHM 2008, usa, October 2008.

[22] I. Jadric, D. Borojevic, and M. Jadric, "A simplified model of a variable speed synchronous generator loaded with diode rectifier," in Proceedings of the Record 28th Annual IEEE Power Electronics Specialists Conference (PESC '97). Formerly Power Conditioning Specialists Conference 1970-71. Power Processing and Electronic Specialists Conference 1972, vol. 1, pp. 497-502, 1997.

[23] A. Cavallo and C. Natale, "Output feedback control based on a high-order sliding manifold approach," Institute of Electrical and Electronics Engineers. Transactions on Automatic Control, vol. 48, no. 3, pp. 469-472, 2003.

[24] M. Presh Nave, K. Priyatharshini, N. Nijandhan, and S. Pradeep, "Adaptive control technique for generator side power system voltage stability at wind power station," in Proceedings of 2 nd International Conference on Intelligent Computing and Applications, vol. 467 of Advances in Intelligent Systems and Computing, pp. 541-550, Springer Singapore, Singapore, 2017.

[25] K. M. Madani and M. Eslami, "Adaptive control for synchronous generators in the presence of bounded inputs," in Proceedings of the 45th IEEE Conference on Decision and Control 2006, (CDC '06), pp. 2014-2019, usa, December 2006.

[26] V. Vakil, M. Karrari, W. Rosehart, and O. P. Malik, "Synchronous generator model identification using adaptive pursuit method," IEE Proceedings: Generation, Transmission and Distribution, vol. 153, no. 2, pp. 247-252, 2006.

[27] A. Isidori, Nonlinear control systems: an introduction, vol. 72, Springer-Verlag, Berlin, Germany, 3rd edition, 1995.

[28] A. Levant and L. Fridman, "Higher-order sliding modes," in Sliding Mode Control In Engineering, vol. 11 of Automation and Control Engineering, Marcel Dekker, 2002.

[29] A. Levant, "Robust exact differentiation via sliding mode technique," Automatica. A Journal of IFAC, the International Federation of Automatic Control, vol. 34, no. 3, pp. 379-384, 1998.

[30] H. Sira-Ramirez and R. Silva-Ortigoza, Control Design Techniques in Power Electronic Devices, Power Systems, Springer, 2006.

[31] A. Cavallo and B. Guida, "Sliding mode control for DC/DC converters," in Proceedings of the 51st Annual Conference on Decision and Control (CDC '12), pp. 7088-7094, December 2012.

[32] M. Endi, Y. Z. Elhalwagy, and A. Hashad, "Three-layer PLC/SCADA system architecture in process automation and data monitoring," in Proceedings of the 2nd International Conference on Computer and Automation Engineering, ICCAE 2010, pp. 774-779, sgp, February 2010.

[33] F. DiCesare, G. Harhalakis, J. M. Proth, M. Silva, and F. B. Vernadat, Practice of Petri Nets in Manufacturing, Springer Netherlands, Dordrecht, 1993.

[34] A. Cavallo, B. Guida, and L. Rubino, "Boost full bridge bidirectional DC/DC converter for supervised aeronautical applications," International Journal of Aerospace Engineering, vol. 2014, Article ID 808374, 2014.

[35] A. Cavallo, G. Canciello, and B. Guida, "Supervisory control of DC-DC bidirectional converter for advanced aeronautic applications," International Journal of Robust and Nonlinear Control, 2017.
[36] F. Gao, Y. Gu, S. Bozhko, G. Asher, and P. Wheeler, "Analysis of droop control methods in DC microgrid," in Proceedings of the 2014 16th European Conference on Power Electronics and Applications, EPE-ECCE Europe 2014, fin, August 2014. 


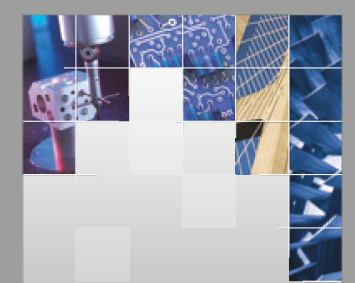

\section{Enfincering}
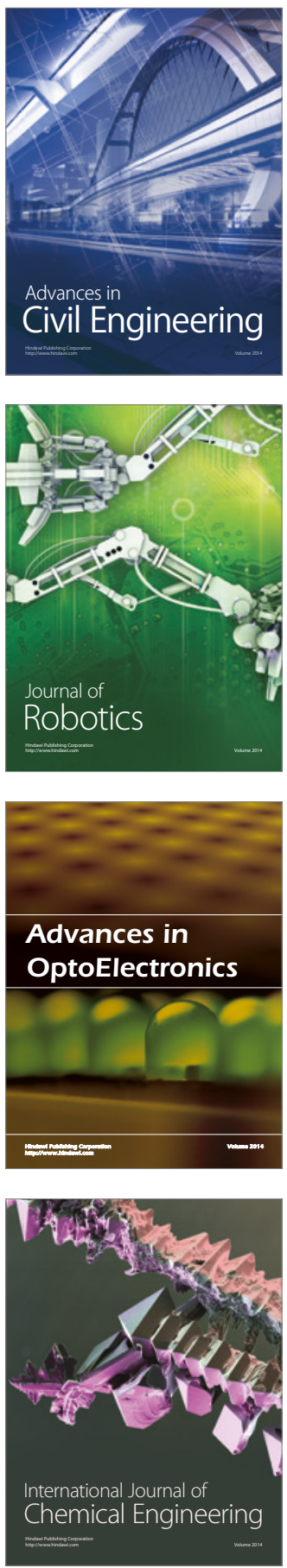

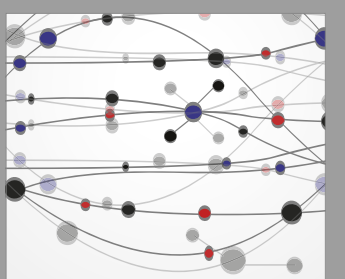

The Scientific World Journal

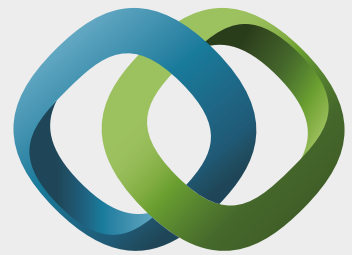

\section{Hindawi}

Submit your manuscripts at

https://www.hindawi.com
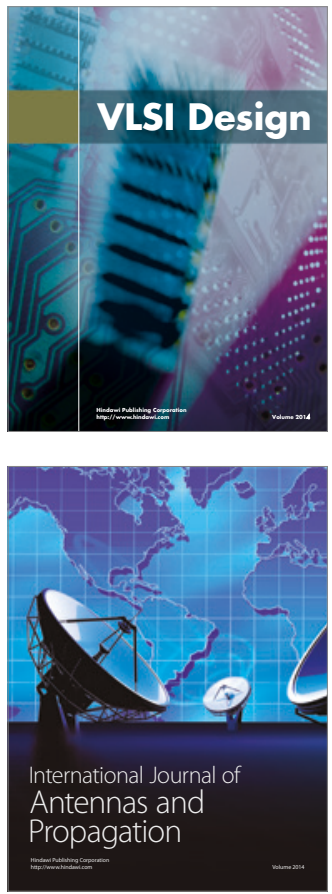

\section{Rotating}

Machinery
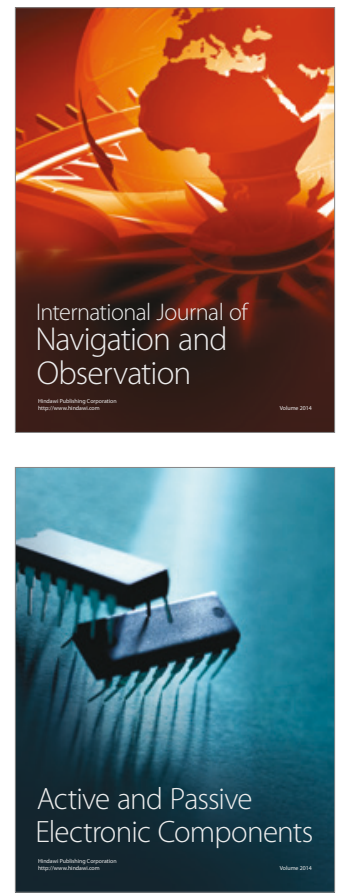
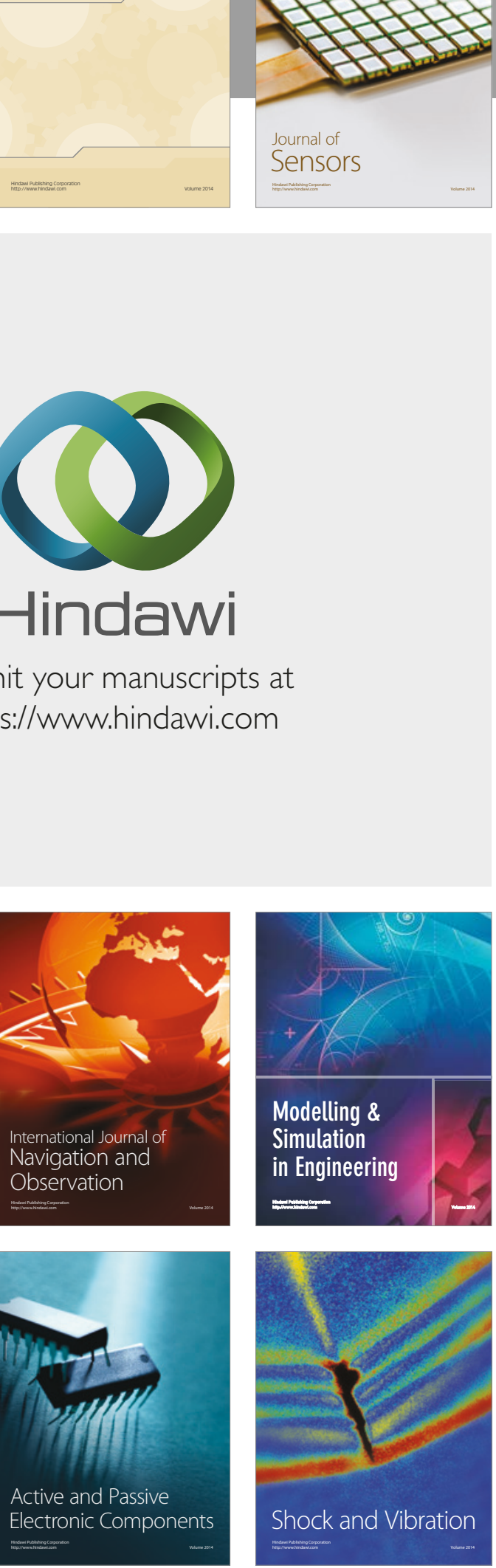
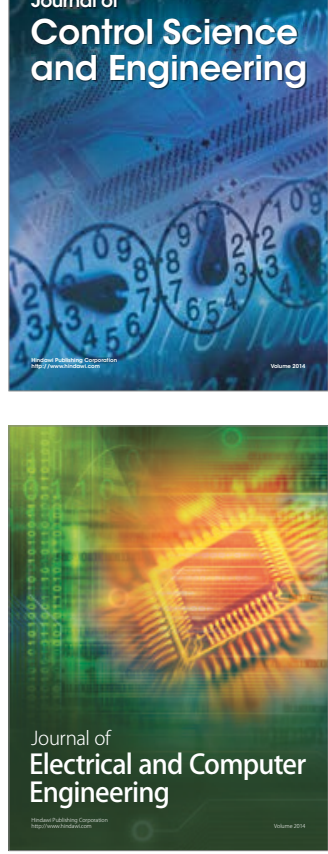

Distributed

Journal of

Control Science

and Engineering
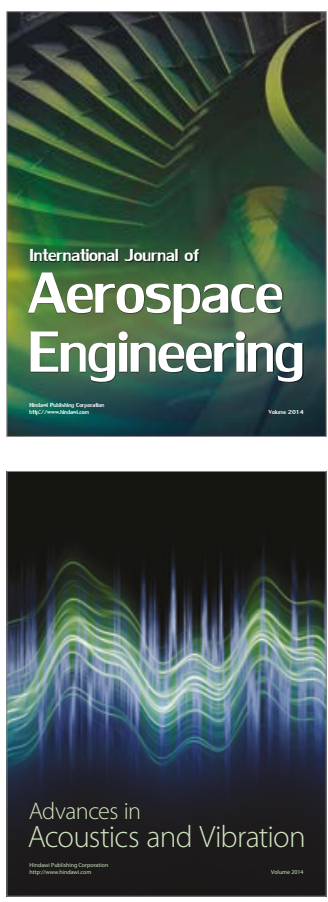

Sensor Networks 